\title{
Recent Advances in Pancreatic MR Imaging: A Guide on How, When, and Why to Perform
}

\author{
Sivasubramanian Srinivasan ${ }^{1, \odot}$ Argha Chatterjee ${ }^{2, \odot}$ \\ ${ }^{1}$ Department of Diagnostic Radiology, Khoo Teck Puat Hospital, \\ Singapore, Singapore \\ 2Department of Radiology and Imaging, Tata Medical Center, \\ Kolkata, India
}

\begin{abstract}
Address for correspondence Argha Chatterjee, MD, PDCC, Department of Radiology and Imaging, Tata Medical Center, Kolkata, West Bengal 700156, India (e-mail: arghachat84@gmail.com).
\end{abstract}

J Gastrointestinal Abdominal Radiol ISGAR 2020;3:2-13

\begin{abstract}
Keywords

- diffusion magnetic resonance imaging

- magnetic resonance imaging

- pancreas

- recent advance

Imaging of the pancreas is often challenging because of its retroperitoneal location and unique set of pathologies. Conventional imaging modalities, such as transabdominal and endoscopic ultrasonography (EUS), computed tomography (CT), and magnetic resonance imaging (MRI), are well described in the literature. However, with modern demand for functional and molecular information from imaging studies, newer imaging modalities and modifications of existing modalities are developed. MRI is widely used as a problem-solving tool in pancreatic pathologies. Magnetic resonance cholangiopancreatography (MRCP) is an excellent technique for the depiction of the pancreatic ductal or biliary ductal pathologies. Newer modification of MRI including secretin MRCP, advanced diffusion-weighted imaging (DWI), perfusion imaging, and tissue composition analysis (fat and fibrosis quantification) add to the arsenal of MRI of the pancreas. In this review, we discuss the evolution of MRI of the pancreas and clinical application of advanced MR sequences.
\end{abstract}

\section{Introduction}

Magnetic resonance imaging (MRI) has evolved over the years with significant improvement in the scan time and image quality with the improvement of MR hardware and software. Present-day MR scanners have up to 30 radiofrequency (RF) channels (receiver pathways) and more than 100 coil segments that create the magnetic field. ${ }^{1}$ A higher number of channels have enabled techniques, such as parallel imaging, to be implemented that have significantly shortened the scan time.

\section{Evolution of MRI of Pancreas}

One of the earliest studies of MR imaging of the pancreas was published by Tscholakoff et al in 1987. ${ }^{2}$ The study was done with small sample size and the scan was performed on a 0.35 Tesla (T) MR machine. Since then, there have been significant improvements seen in software and hardware in the quality with reduced scan time. The earliest literature on MR cholangiopancreatography (MRCP) was around in the early 1990s. ${ }^{3}$ Three decades ago only T1 and T2 sequences were available for the abdomen. Currently, the field strength of the
MR machine in most centers performing abdominal imaging is 1.5 or $3 \mathrm{~T}_{0}^{4,5}$ Higher field strength allows an improved signal to noise ratio, thereby allowing advanced sequences such as diffusion-weighted imaging (DWI) to be performed. Increased field strength also improves contrast resolution with better detection of focal lesions in postcontrast T1-weighted images and increasing conspicuity of lesions in T2-weighted images. ${ }^{6}$

Today, the main role of conventional MRI of the pancreas is to better characterize the cystic and solid parenchymal lesions and evaluation of pancreatic ductal anatomy. However, newer sequences, such as DWI, perfusion imaging, fat, and fibrosis quantification, provide additional information about focal and diffuse pancreatic pathologies (-Table 1 ).

\section{Normal Morphology of Pancreas in MRI}

The pancreas has an inherent high T1 signal due to the presence of water-soluble proteins, paramagnetic substances, such as manganese within the cells, and numerous endoplasmic reticula in the exocrine cells ( - Fig. 1). There is a progressive loss of this high T1 signal with increasing severity
DOI https://doi.org/ 10.1055/s-0040-1709080 ISSN 2581-9933.
License terms

(ㅇ) (1) $\ominus \circledast$ 
Table 1 Advanced pancreatic MRI sequences in a nutshell

\begin{tabular}{|c|c|c|}
\hline Modality & Use & Comment \\
\hline DWI & $\begin{array}{l}\text { Identification of early mild } \\
\text { and focal pancreatitis } \\
\text { Identification of small liver } \\
\text { and nodal metastases in pan- } \\
\text { creatic adenocarcinoma } \\
\text { Identification of subtle pan- } \\
\text { creatic primary neoplasm } \\
\text { Identification of solid nodules } \\
\text { in cystic neoplasm } \\
\text { Characterization of focal pan- } \\
\text { creatic lesion [smaller role] }\end{array}$ & $\begin{array}{l}\text { Routinely used. } \\
\text { Diffusion kurtosis, } \\
\text { tensor imaging, and } \\
\text { IVIM are in early } \\
\text { clinical research }\end{array}$ \\
\hline $\begin{array}{l}\text { MR } \\
\text { perfusion }\end{array}$ & $\begin{array}{l}\text { Differentiation of neoplasm } \\
\text { from benign process } \\
\text { Monitoring response to } \\
\text { antiangiogenic therapy }\end{array}$ & $\begin{array}{l}\text { DCE MR routinely } \\
\text { used }\end{array}$ \\
\hline $\begin{array}{l}\text { T1 relax- } \\
\text { ometry }\end{array}$ & $\begin{array}{l}\text { Diagnosis and monitoring of } \\
\text { chronic pancreatitis }\end{array}$ & Limited clinical use \\
\hline $\begin{array}{l}\mathrm{T} 2^{*} / \mathrm{R} 2^{*} \\
\text { mapping }\end{array}$ & $\begin{array}{l}\text { Parenchymal iron } \\
\text { quantification }\end{array}$ & Early research \\
\hline $\begin{array}{l}\text { Fat quan- } \\
\text { tification }\end{array}$ & $\begin{array}{l}\text { Surrogate marker of meta- } \\
\text { bolic disease }\end{array}$ & Research \\
\hline $\begin{array}{l}\text { MR elas- } \\
\text { tography }\end{array}$ & $\begin{array}{l}\text { Differentiation of adenocarci- } \\
\text { noma and focal autoimmune } \\
\text { pancreatitis }\end{array}$ & Research \\
\hline $\begin{array}{l}\text { Secretin } \\
\text { MRCP }\end{array}$ & $\begin{array}{l}\text { Uncover ductal commu- } \\
\text { nication of cystic lesions } \\
\text { (branched IPMN) } \\
\text { Assessment of exocrine } \\
\text { function of pancreas } \\
\text { Demonstration of ductal leak }\end{array}$ & $\begin{array}{l}\text { Limited use, not } \\
\text { available in India }\end{array}$ \\
\hline
\end{tabular}

Abbreviations: DCE, dynamic contrast enhancement; DWI, diffusion-weighted imaging; IPMN, intraductal papillary mucinous neoplasm; IVIM, intravoxel incoherent motion; MRCP, magnetic resonance cholangiopancreatography; MRI, magnetic resonance imaging.

in chronic pancreatitis ( - Fig. 2). This change is quantified T1-relaxometry (see the section "T1 Mapping/Relaxometry"). In T2-weighted images, the pancreas appears slightly hyperintense to the skeletal muscles.

\section{Conventional Pancreatic MRI Protocol}

\section{Patient Preparation}

The patient should be on fast for at least 4 hours to reduce the stomach and duodenal contents. Fasting also improves the distension of the gallbladder and reduced peristalsis of the small bowel. The signal from fluid in the duodenal lumen can be suppressed by commercially available negative oral contrast (e.g., LumiVision, a manganese suspension). Other alternatives include blueberry or pineapple juice or dilute solution of gadolinium containing contrast medium..$^{7-10}$

Conventional MRI of the pancreas routinely consists of the following sequences:

\section{T1-Weighted Image}

T1 signal of the pancreas is reduced in conditions such as inflammation and neoplasm. T1-weighted image is very useful to assess bleed and to see the changes in the peripancreatic fat. Breath-hold fast acquisition spoiled gradient sequences with short time to echo (TE) are commonly used. In-phase and out-phase sequences are useful in assessing fat within the pancreas and are routinely used in most centers. ${ }^{1,6,11,12}$ The T1-weighted image acts as a baseline for the assessment of postcontrast T1-weighted sequences.

\section{T1-Weighted Postcontrast Image}

Breath-hold T1-weighted sequences are used for postcontrast MRI. These are three dimensional (3D) spoiled gradient echo sequences with fat suppression. The protocol for the postcontrast T1-weighted sequence is provided in - Table 2 . Normal pancreatic parenchyma mostly enhances the early arterial phase, while most adenocarcinomas show low and delayed enhancement ( - Fig. 3). Neuroendocrine tumors show early enhancement.

\section{T2-Weighted Image}

The T2-weighted sequence can either be single-shot fast spin-echo (SSFSE), or half Fourier acquisition single-shot turbo spine-echo (HASTE), or multishot echo sequence. These sequences are acquired with breath-hold technique. Image quality is better with SSFSE compared with FSE or TSE sequences mainly because of faster acquisition. However, the contrast resolution and signal-noise ratio are affected due to longer echo train length and $\mathrm{T} 2$ decay. The fluid signal within or outside the pancreas is well visualized in T2 sequences, especially after fat suppression. ${ }^{3-17}$

\section{Magnetic Resonance Cholangiopancreatography}

MRCP sequence is a heavily T2-weighted sequence (FSE or SSFSE sequence) that enhances the fluid signals while suppressing other signals in the background and, therefore, shows the ductal anatomy and cystic lesions in great detail (-Fig. 4). SSFSE sequences are faster and produce fewer motion artifacts. Two dimensional (2D) sequences are performed with single-breath-hold and are thick slab images. The 3D MRCP is performed by respiratory triggering and requires uniform breath-hold technique. In the 3D MRCP sequence, thin contiguous images are obtained that can be reconstructed by thin or thick maximum intensity projections (MIP). The thin MIP reconstructions help in assessing the anatomy of the ducts ( - Fig. 4 ); the relationship is between focal mass or cyst and duct ( $\boldsymbol{- \text { Fig. }} \mathbf{5}$ ); and dilatation, strictures, or stones in the ducts $(\boldsymbol{-}$ Fig. $\mathbf{6}){ }^{18-21}$

\section{Quantitative Imaging and Newer Applications}

Although MRI has been established as an excellent modality to depict the anatomy of the pancreas, newer sequences are being developed for quantitative assessment and improved resolution. ${ }^{4}$

\section{Secretin MRCP}

Secretin is a peptide hormone that stimulates bicarbonate-rich fluid secretion from the pancreas and increases the 




Fig. 1 Axial T1 weighted fat-suppressed image showing relatively hyperintense pancreas (arrow).
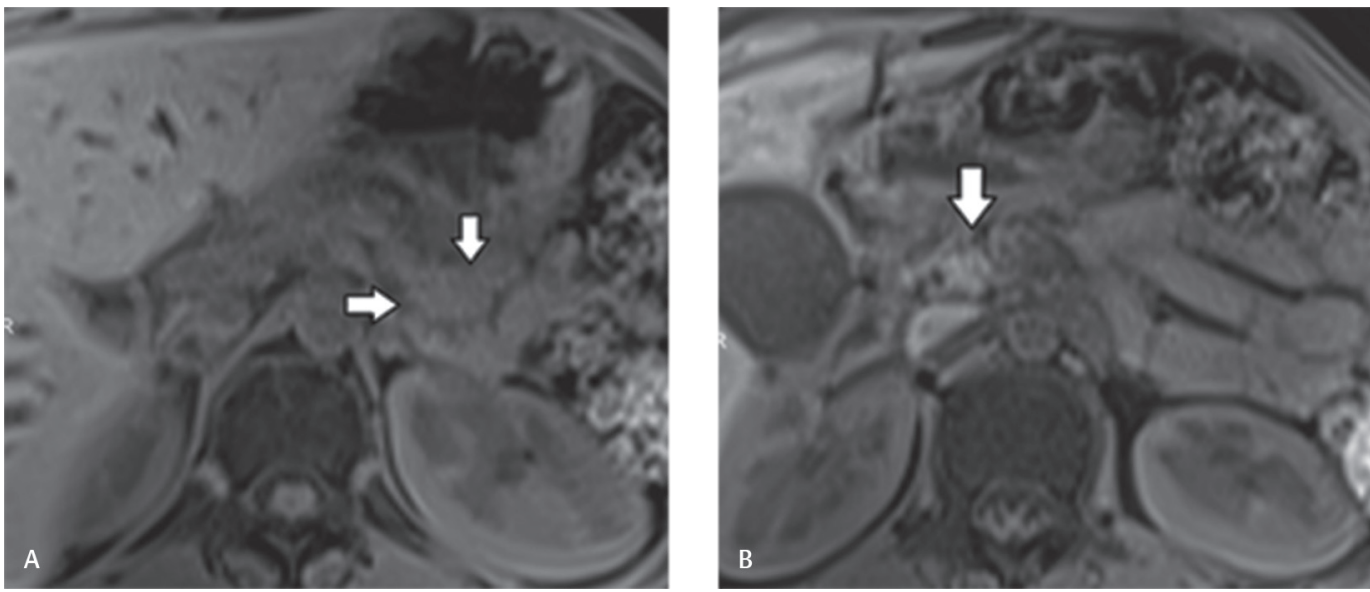

Fig. 2 Loss of T1 signal in chronic pancreatitis. Axial T1-weighted fat-suppressed image at the level of the pancreatic tail (A) shows isointense parenchyma with loss of T1 signal (between arrows). Compare with retained normal high T1 signal in the pancreatic head (arrow in B).

Table 2 Protocol for postcontrast T1-weighted sequence

\begin{tabular}{|l|l|}
\hline Contrast volume & $0.1 \mathrm{~mL} / \mathrm{kg}$ \\
\hline Rate & $2 \mathrm{~mL} / \mathrm{s}$ followed by $20 \mathrm{~mL}$ saline flush \\
\hline Arterial phase & $20-25$ seconds delay \\
\hline Portal venous phase & $55 \mathrm{~s}$ \\
\hline Delayed & $90-180 \mathrm{~s}$ \\
\hline Sequence & $\begin{array}{l}\text { VIBE/LAVA (3D spoiled gradient } \\
\text { T1-weighted sequence) }\end{array}$ \\
\hline
\end{tabular}

Abbreviations: 3D, three-dimensional; LAVA, liver acquisition with volume acceleration; VIBE, volumetric interpolated breath-hold examination. tone of the sphincter of Oddi. Injection of secretin before MRCP imaging distends pancreatic ducts and uncovers small ductal communications. Secretin induced MRCP is also an excellent noninvasive imaging technique to evaluate the exocrine function of the pancreas. However, this study has limited applicability due to limited availability and high cost of secretin. $4,22,23$

The recommended dose of secretin is around $0.2 \mu \mathrm{g} / \mathrm{kg}$. The peak action of the injected secretin is around 3 to 5 minutes after administration and the duodenal lumen gets filled with the bicarbonate rich fluid after 5 minutes and the maximum
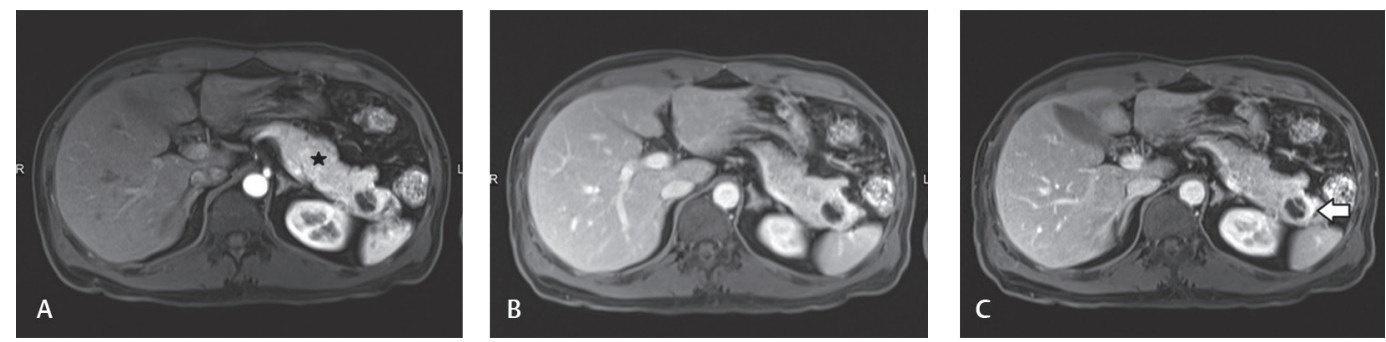

Fig. 3 Dynamic/ multiphasic postcontrast T1-weighted images of the pancreas. Early arterial (A), late arterial (B), and equilibrium (C) phase show early enhancement of pancreatic parenchyma (asterisk in A) and delayed enhancement of the wall of the cystic lesion at the pancreatic tail (arrow in C). Case of mucinous cystic neoplasm of the pancreas. 


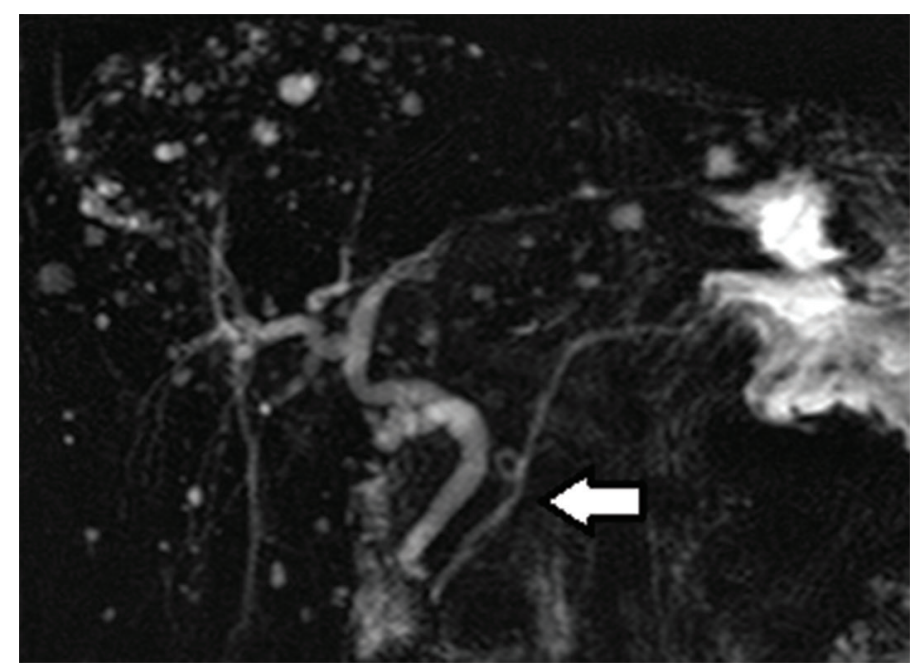

Fig. 4 Demonstration of ductal anatomy in ansa pancreatica. Thick slab 2D MRCP sequence shows a characteristic loop in the main pancreatic duct (arrow). 2D, two-dimensional; MRCP, magnetic resonance cholangiopancreatography.
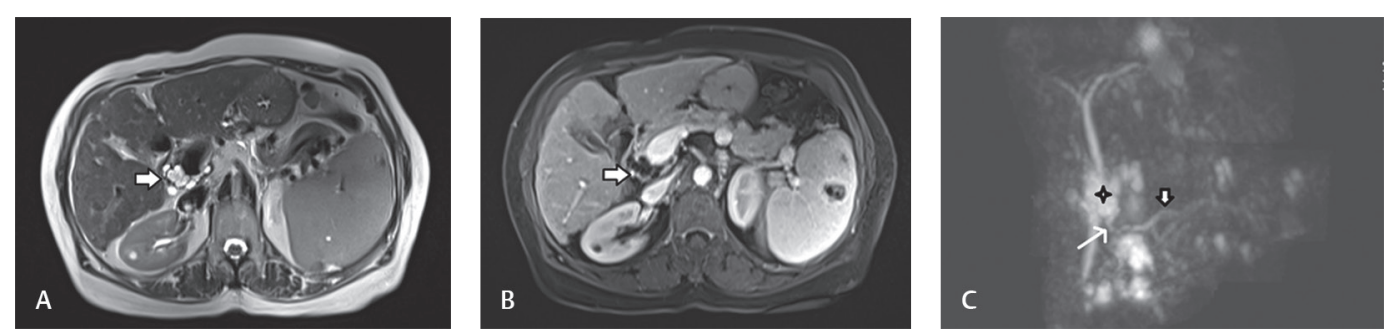

Fig. 5 Demonstration of ductal communication between side branch intraductal papillary mucinous neoplasm (IPMN) of the pancreas and main pancreatic duct. A-B, Axial T2-weighted (A) and postcontrast T1-weighted (B) images show a multiloculated cystic lesion in the pancreatic head (arrow). (C) Maximum intensity projection of thin slab 3D MRCP shows thin ductal communication (thin arrow) between the cystic lesion (asterisk) and main pancreatic duct (thick arrow), establishing the diagnosis of side branch IPMN. 3D, three-dimensional; MRCP, magnetic resonance cholangiopancreatography.

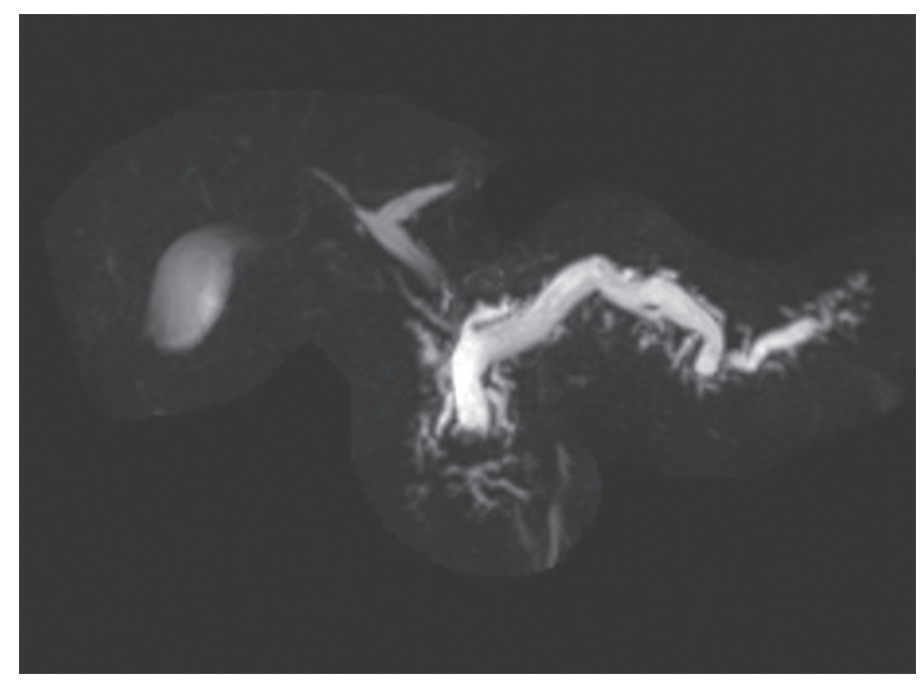

Fig. 6 Demonstration of altered ductal morphology in chronic pancreatitis. Maximum intensity projection of thin slab 3D MRCP shows dilated main pancreatic duct with prominent side branches. 3D, three-dimensional; MRCP, magnetic resonance cholangiopancreatography.

output is around 6 and 8 minutes. The patient is usually fasted for at least 4 hours and duodenal fluid is suppressed by a negative oral contrast agent such as very dilute gadolinium. After injection of secretin, SSTSE thick slab MRCP image (30-70-mm thickness) is obtained in the coronal plane with a breath-hold or respiratory trigger for 10 minutes postinjection, at 30-second intervals. This study is ended with a respiratory-triggered MRCP sequence. Secretin MRCP is used and volume of blood plasma $(\mathrm{Vp})$ within of the pancreas semiquantitatively. Filling of the duodenum is graded as follows: grade 1, fluid filling is confined to the duodenal bulb; grade 2, fluid reached up to the second portion of the 

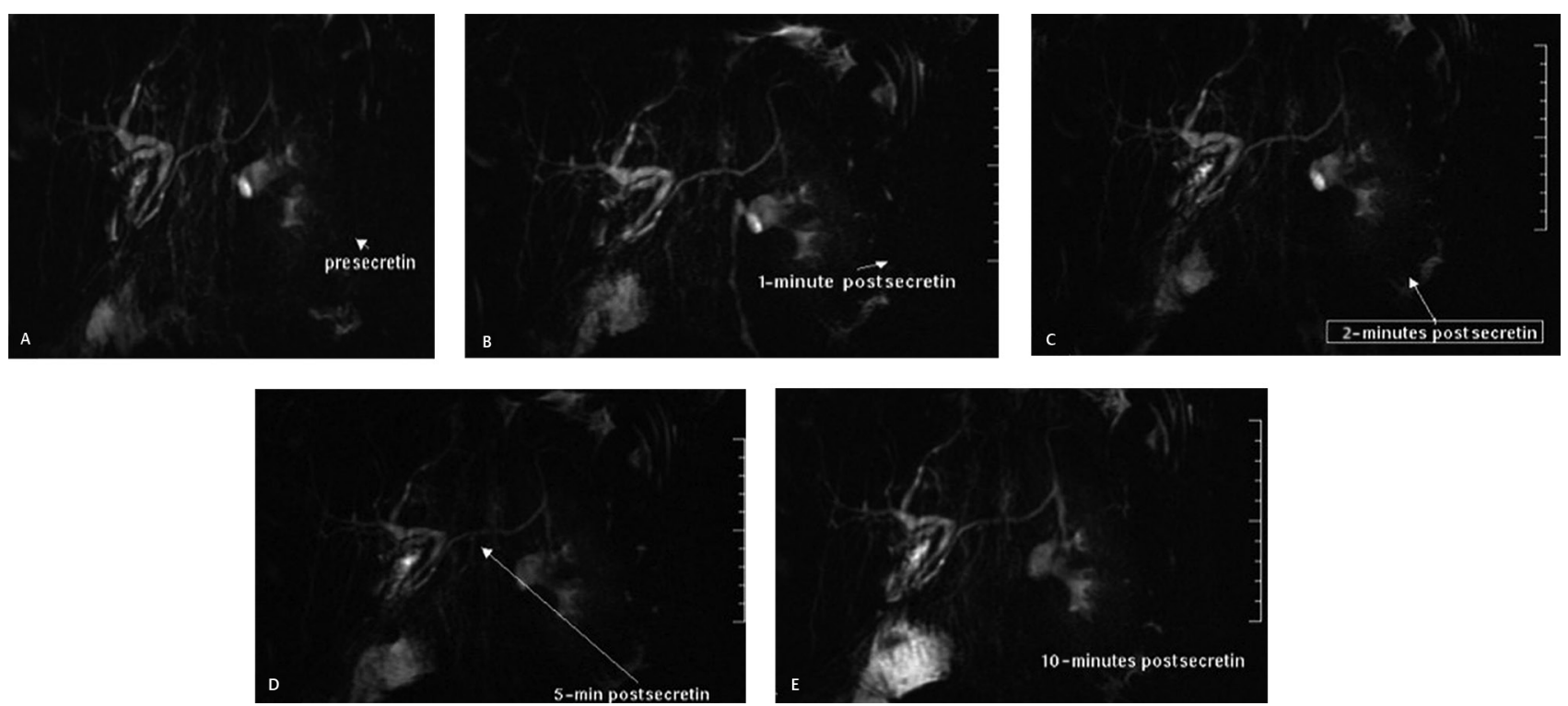

Fig. 7 Secretin MRCP in a 47-year-old woman with recurrent abdominal pain and vomiting. (A) Preinjection, (B) 1 minute, (C) 2 minutes, (D) 5 minutes, and (E) 10 minutes of postinjection images. A mild increase in diameter of pancreatic duct 1 or 2 minutes following administration of intravenous secretin with the return to normal caliber on subsequent images. Mild exocrine insufficiency is demonstrated by filling up of up to the third portion of duodenum in the 10-minute postinjection image (grade 3 response). (Image courtesy: Dr. Avinash Kambadakone Ramesh, Massachusetts General Hospital, Boston, Massachusetts, United States]. MRCP, magnetic resonance cholangiopancreatography.

duodenum; grade 3, filling up to the third portion of the duodenum; and grade 4 , complete filling of duodenum and portion of jejunum (-Fig. 7). ${ }^{24}$

Secretin MRCP can uncover small ductal channels and communication aiding in the differentiation of branched IPMN and other cystic lesions of the pancreas. ${ }^{25}$ Secretin MRCP is also useful in the identification of pancreatic duct leak in the postoperative pancreas ${ }^{26}$ and ductal anomalies such as pancreas divisum, annular pancreas, and anomalous pancreaticobiliary junction.

\section{Perfusion Imaging}

Regional tissue perfusion can be assessed based on the uptake and washout of contrast agents. Dynamic contrast enhancement (DCE) MRI uses repeated acquisition of T1-weighted gradient weighted images at short intervals and evaluated the change in signal intensity of tissue due to contrast enhancement. Dynamic susceptibility contrast (DSC) MRI uses a signal drop in $2^{*}$-weighted images in a similar manner. Arterial spin labeling is a novel technique that uses "intrinsic contrast" by saturating water protons in arterial blood. ${ }^{27}$

DCE is the most commonly performed technique of MR perfusion. It can be assessed qualitatively by observing different phases and by generating a time-intensity curve..$^{28}$ Semiquantitative parameters can be calculated from the curve include maximal initial slope, peak signal intensity, and washout gradient. Quantitative parameters include transfer constant $\left(\mathrm{K}_{\text {trans }}\right)$, volume of extravascular extracellular space $\left(\mathrm{V}_{\mathrm{e}}\right)$, and volume of blood plasma $\left(\mathrm{V}_{\mathrm{p}}\right)$ within the region of interest and rate constant $\left(\mathrm{K}_{\mathrm{ep}}\right)$. $\mathrm{K}_{\text {trans }}$ is a marker of capillary permeability when the overall tissue permeability is low and it represents the tissue blood flow when the overall tissue permeability is very high.
MR perfusion is a potentially useful tool in the differentiation of neoplasms and tissue with different perfusion and assessment of response to antiangiogenic therapy. ${ }^{29}$

\section{Diffusion-Weighted Imaging}

The principle of DWI is in certain types of pathologies that the random Brownian motion of water molecules in the tissue is restricted. Diffusion restriction typically occurs in tissues due to increased cell count per unit area (neoplasia) and increased cell size (cytotoxic edema and inflammation) resulting in a decrease in interstitial space, as well as in presence of thick and dense interstitial tissue (fibrosis) or material (pus or proteinaceous material). Pathologies, such as inflammation, tumor, and fibrosis, cause restriction of this motion and appear hyperintense on DWI with a low-apparent diffusion coefficient (ADC) values.

DWI is a modification of spin-echo T20weighted imaging that utilizes the "ultrafast" echo-planar imaging technique. Two opposing gradients are applied before and after the 180-degree refocusing pulse. The first gradient induces a phase shift in the water protons that is canceled by the second gradient, provided the protons are stationary or have restricted motion. On the other hand, free protons are completely dephased by the second gradient. Therefore, the tissue with restricted motion returns higher signals from water protons. The amount of diffusion "weighting" is indicated by the b-value of the sequences. In clinical practice, DWI is usually obtained with two or more $b$-values. The low $b$-value images $\left(b<200\right.$ second $\left.\mathrm{mm}^{2}\right)$ are similar to T2-weighted images and higher $b$-values $\left(b>800\right.$ second $\mathrm{mm}^{2}$ ) are more diffusion weighted. The DWI images can be used to generate the ADC maps. Lesions with restricted diffusion appear hyperintense in high $b$-value DWI images and hypointense in 
ADC maps. ADC of a lesion can be quantified by drawing an ROI (region of interest) on the ADC map in most commercial MR scanners. ADC is represented by the unit $\mathrm{mm}^{2} / \mathrm{s}$.

Normal pancreas should be homogeneous and slightly hyperintense DWI with slightly low signal in ADC. The average $\mathrm{ADC}$ of the pancreas is reported to be $1.6 \times 10 \mathrm{~mm}^{2} / \mathrm{s}^{30}$ Heterogeneous ADC distribution and increased ADC values are reported in type- 1 diabetes mellitus along with the reduction in pancreatic volume. ${ }^{31}$ Common clinical utility of DWI in pancreatic imaging is given in - Table 1 .

\section{Pancreatic Inflammation}

Acute inflammation reduces the ADC of pancreatic tissue. The average ADC of acute pancreatitis is reported to be approximately $1.2-1.6 \times 10^{-3} \mathrm{~mm}^{2} / \mathrm{s}$ depending on the severity of pancreatitis. ${ }^{32,33}$ ADC values are shown to correlate with the Balthazar score of severity of pancreatitis with lower values representing a higher score. ${ }^{34}$ DWI can be used to identify mild acute interstitial pancreatitis especially in patients in whom contrast study cannot be done $^{35}$ (-Fig. 8). With successful treatment of pancreatitis, ADC values are shown to normalize. ${ }^{36}$ Caution should be exercised in presence of necrotizing pancreatitis, as the necrotic area may show higher ADC values and lower signal on DWI due to loss of cell membrane integrity ("facilitated diffusion" $)^{32}$ (-Fig. 9). Therefore, it is important to correlate with contrast-enhanced images when available. Areas of pancreatic necrosis do not show contrast enhancement. Some authors have suggested that the presence of superadded infection in acute pancreatic or peripancreatic collection may show diffusion restriction ${ }^{37}$; however, this is not universally accepted, and infection is often proven by aspiration.

In chronic pancreatitis, pancreatic parenchyma is progressively replaced by fibrosis. ADC values decrease with increasing pancreatic fibrosis. ${ }^{38}$ DWI is shown to diagnose chronic pancreatitis with high specificity..$^{39}$

Autoimmune pancreatitis (AP) can show markedly low$A D C$ value (very high signal on $D W I$ ). ADC values in AP can be lower than that of adenocarcinoma. ${ }^{40} \mathrm{ADC}$ is shown to be even lower in symptomatic patients. As autoimmune pancreatitis is often focal and shows strong restriction in diffusion, it is sometimes mistaken for pancreatic cancer. ADC values are useful in monitoring treatment response. ${ }^{41}$

\section{Solid Pancreatic Lesions}

The most common solid neoplasm of the pancreas is adenocarcinoma, which is often isoattenuating on computed tomography (CT) scan and therefore difficult to delineate. DWI helps in identifying small, subtle pancreatic lesions (-Fig. 10). DWI has shown similar or better diagnostic performance to contrast-enhanced MRI in identifying pancreatic adenocarcinoma. ${ }^{42}$ However, lesions are sometimes difficult to differentiate from upstream atrophic pancreatic parenchyma because of decreased ADC value of upstream pancreas owing to fibrosis. ${ }^{43}$ DWI is also helpful in identifying subtle metastasis in the liver and lymph nodes ${ }^{44}$ ( - Fig. 11). DWI is shown to more sensitive in picking up small neuroendocrine tumors and liver metastases.

\section{Cystic Pancreatic Lesions}

DWI helps in the identification of small mural nodules in cystic neoplasms such as intraductal papillary mucinous neoplasm (IPMN). A purely cystic lesion is more likely to be benign.

\section{Newer Diffusion Techniques}

Normal tissue is composed not only of interstitium and cells but also small blood vessels. Water diffusion in tissues is a combination of free (or coherent) diffusion through the interstitium and perfusion (or incoherent diffusion) through the microcapillary network. Diffusion of water protons detected by conventional DWI images is based on a monoexponential model which does not take into account component of the microcapillary perfusion of tissue. This is one of the reasons why the diffusion coefficient calculated by conventional DWI is called the "apparent" diffusion coefficient. However, intravoxel incoherent motion (IVIM) MRI utilizes multiple $b$-values in a biexponential model that can calculate the component of tissue microcapillary perfusion. In addition to the conventional ADC value, IVIM also provides $D$-value, $D^{*}$-value, and $f$-value (perfusion fraction). $D$-value (or slow ADC value) is the true diffusion coefficient and reflects the tissue microstructure. The $D^{*}$-value (or fast ADC value), also referred to as the pseudo-diffusion coefficient, represents the perfusion effect of the incoherent microcirculation within the voxel. The proportion of the perfusion effect is defined as the perfusion fraction $(f)$. Since pancreatic adenocarcinoma is hypovascular compared with normal
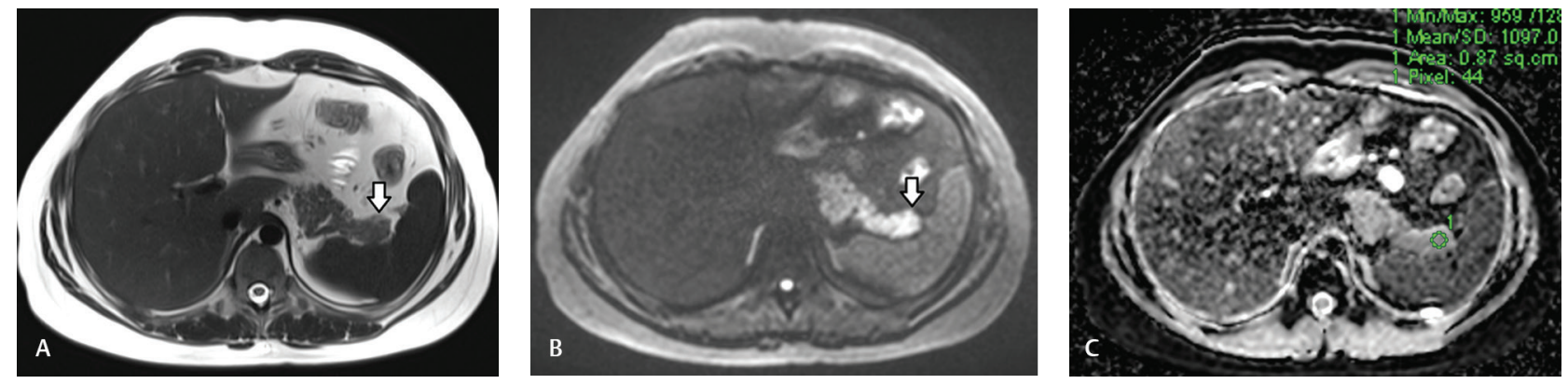

Fig. 8 Mild acute pancreatitis detected in diffusion-weighted imaging (DWI). (A) axial T2-weighted HASTE image shows subtle loss of lobulations of the pancreatic tail (arrow) without any enlargement, increased T2-signal or edema. (B) axial DWI $\left(b=800\right.$ second $\left.\mathrm{mm}^{2}\right)$ shows focal hyperintensity of the pancreatic tail (arrow). (C) apparent diffusion coefficient (ADC) map shows hypointensity in the corresponding with a low ADC value of $1.10^{-3} \mathrm{~mm}^{2} / \mathrm{s}$. HASTE, half Fourier acquisition single-shot turbo spine-echo. 

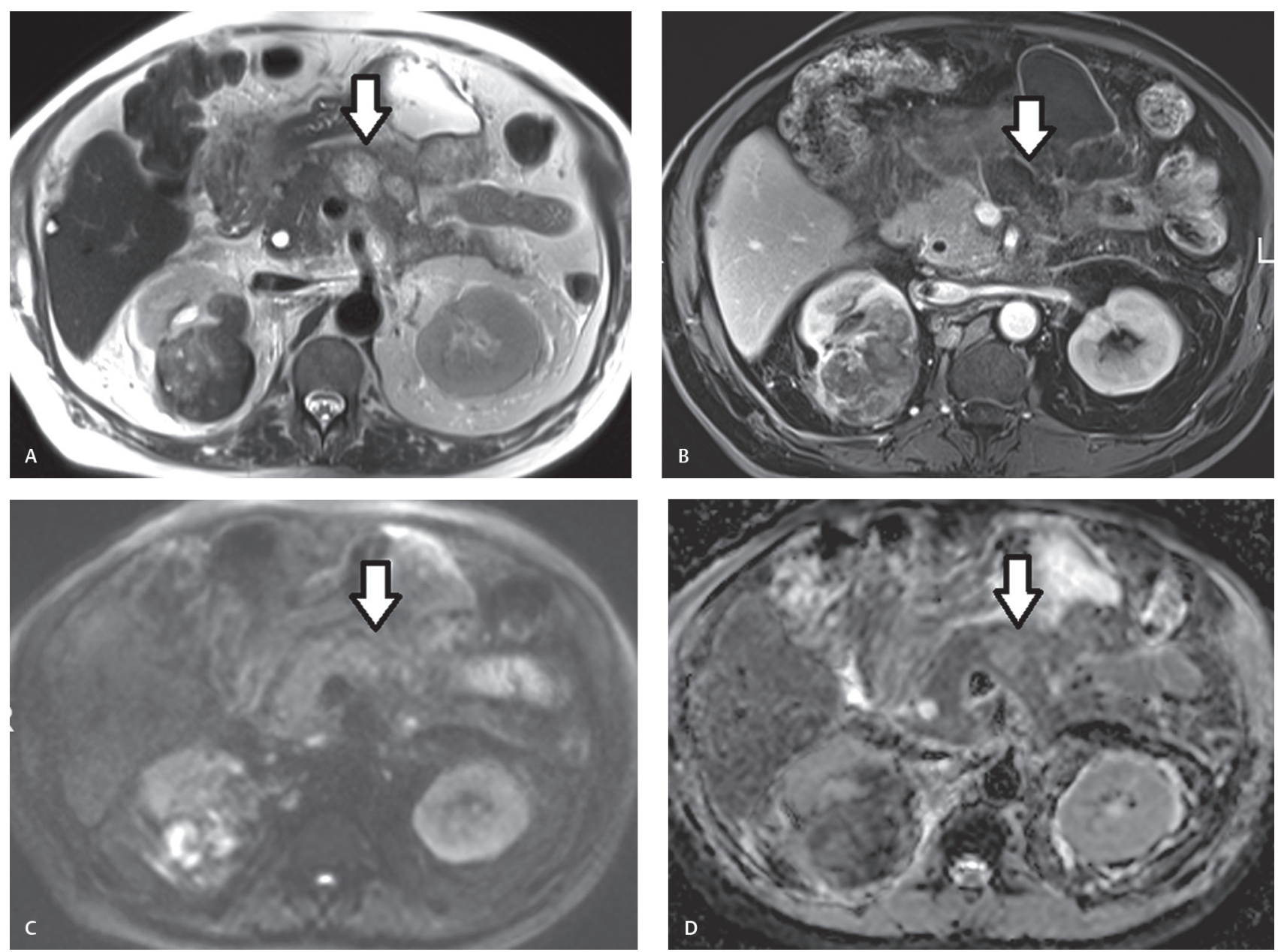

Fig. 9 Necrotizing pancreatitis with facilitated diffusion. Axial T2-weighted HASTE image (A) shows a bulky edematous pancreas with a focal area of high signal in body portion (arrow) that shows no contrast enhancement in postcontrast T1-weighted image (arrow) (B). (C) Diffusionweighted image $\left(b=800\right.$ second $\left.\mathrm{mm}^{2}\right)$ shows no hyperintensity in the corresponding area with high signal on apparent diffusion coefficient (ADC) map (D) suggesting high ADC value. HASTE, half Fourier acquisition single-shot turbo spine-echo.

pancreatic parenchyma because of the destruction of the normal capillary network, adenocarcinoma shows lower perfusion fraction $(f) .^{45}$

Free diffusion is isotropic, that is, occurs in all directions. However, in biological tissue diffusion is anisotropic, that is, more in one or more direction and restricted in others. This is due to the presence of cell membranes, myelin sheath, or tissue architecture. Diffusion tensor imaging (DTI) detects the degree of the restriction diffusion of water molecules and evaluates the different directions of diffusion. DTI can provide some details on the microstructure of tissues that are not available in conventional imaging. ${ }^{46}$ There are five main parameters in the DTI, including mean diffusivity (MD), three eigenvalues $\lambda 1, \lambda 2, \lambda 3$, and fractional anisotropy (FA). MD is theoretically more representative of the diffusivity of water protons. The FA represents the fraction of anisotropic water diffusion. Nissan et al showed that DTI parameters are lower in pancreatic adenocacinoma than that of the distal normal pancreatic tissue. ${ }^{47} \mathrm{FA}$ and mean $\mathrm{ADC}$ were found to lower in acute pancreatitis compared with the normal pancreas. ${ }^{48}$

Diffusion kurtosis imaging (DKI) utilizes a diffusion model that addresses the nonuniform (non-Gaussian) movement of water protons. In this model, the heterogeneity of tissue is taken into account and DKI is supposed to represent the complex microstructure of tissue. DKI is still in its early research phase. It is technically demanding and requires the acquisition of high and very high $b$-values. The parameters obtained from DKI are mean kurtosis (MK) and corrected diffusion coefficient $\left(D_{K}\right)$. $D_{K}$ is shown to be able to differentiate between tumor and normal tissue, ${ }^{49}$ correlate with $\mathrm{HbA1}_{c}$ levels, and may potentially serve as a biomarker of glycemic control. $^{50}$

\section{Limitations of Diffusion Imaging}

The major technical limitations of DWI are the inherent low signal-to-noise ratio (SNR), low spatial resolution, and susceptibility to artifacts. SNR can be improved in $3 \mathrm{~T}$ at the cost of more artifacts. SNR is also improved by smaller matrix size, larger FOV, shorter TE, and use of free-breathing sequences. ${ }^{4}$ Newer techniques, such as zoomed EPIDWI (ZOOMit, Siemens Healthcare, Erlangen, Germany) used 2D spatially-selective RF excitation pulses combined with a reduction in the FOV in the phase-encoding direction leading to improved spatial resolution and decreased 



Fig. 10 Subtle pancreatic mass demonstrated in diffusion-weighted imaging (DWI). (A), contrast-enhanced axial CT shows atrophic pancreas with abrupt duct cutoff and altered areas of increased enhancement in the body of the pancreas. (B, C) Fat-suppressed T2-weighted axial HASTE (B) and postcontrast T1-weighted image shows subtle ill-defined hyperintense mildly enhancing lesion in the body portion. (D), coronal 3D MRCP in maximum intensity projection shows abrupt cut-off of duct in the same location. (E), axial DWI $\left(b=800\right.$ second $\left.\mathrm{mm}^{2}\right)$ clearly shows a hyperintense lesion in the corresponding location. Compare the conspicuity of the lesion in DWI to that in other images. Biopsy revealed adenocarcinoma. 3D, three-dimensional; HASTE, half Fourier acquisition single-shot turbo spine-echo; MRCP, magnetic resonance cholangiopancreatography.
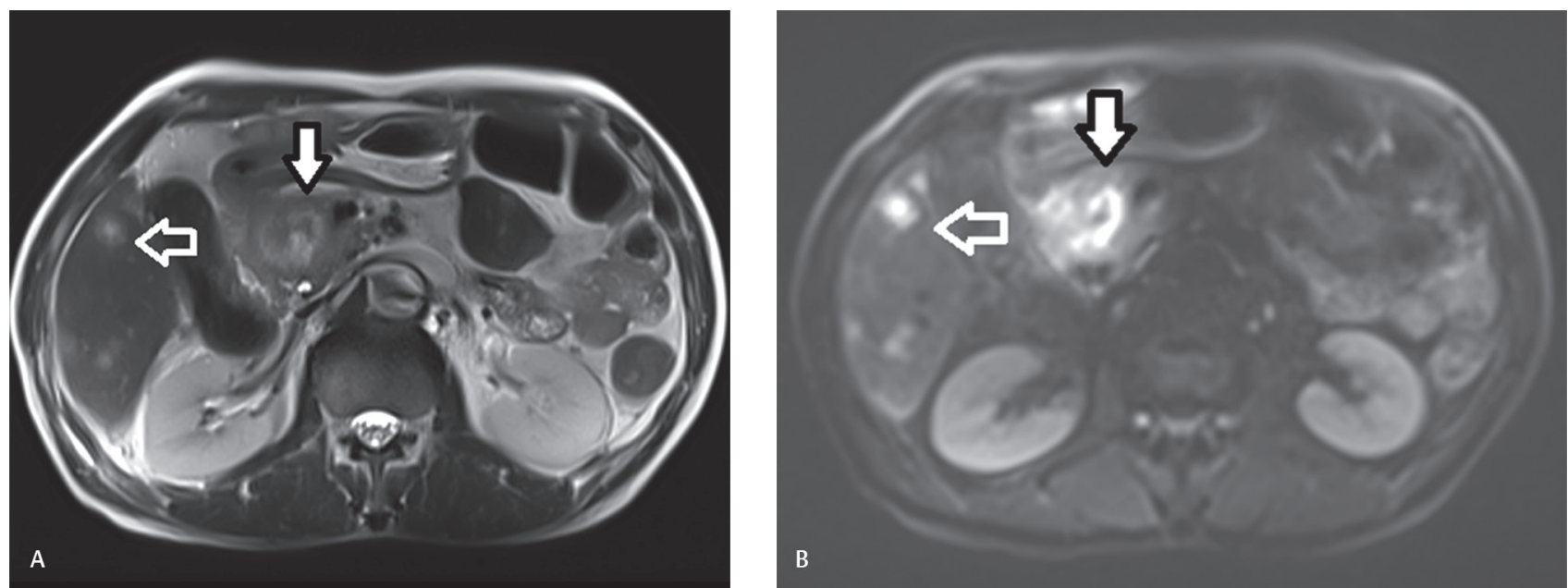

Fig. 11 Demonstration of liver metastases in diffusion-weighted imaging (DWI). (A) Axial T2-weighted HASTE image shows a well-defined hyperintense mass lesion in the head of the pancreas (solid arrow) with few ill-defined faintly hyperintense nodules in the liver (open arrow). (B), Axial DWI $\left(b=800\right.$ second $\left.\mathrm{mm}^{2}\right)$ offers a much better demonstration of liver nodules (open arrow). HASTE, half Fourier acquisition single-shot turbo spine-echo. 
susceptibility artifacts. ${ }^{51}$ To improve image quality with similar FOV, sequences, such as readout-segmented echo-planar diffusion methods (rs-DWI), have been developed (RESOLVE [readout segmentation of long variable echo trains], Siemens Healthcare, Erlangen, Germany).

\section{Fat Quantification}

Pancreatic fat content increases with age and body mass index. ${ }^{52}$ Although pancreatic fat content may be increased in patients with diabetes and prediabetes, ${ }^{53}$ this relationship is not established. More recent studies suggest that the fat content of pancreatic tail may be related to the future development of diabetes. ${ }^{54}$

Fat quantification can be done by various techniques including two-point Dixon, three-point Dixon, and chemical shift imaging. Dixon sequence generates a set of in-phase, out-phase, fat-only, and water-only images from the same acquisition. Fat containing lesions are hypointense in opposed-phase images ("signal drop") and hyperintense in fat-only images ( - Fig. 12).

MRI proton density fat fraction (MRI-PDFF) is obtained by a quantitative DIXON sequence that utilizes multiple TE. This sequence automatically generates maps of fat fraction, $\mathrm{T} 2, \mathrm{~T}^{*}$, and $\mathrm{R} 2^{*}$. The fat fraction can be calculated from placing the ROI in the pancreas (-Figs. 13 and $\mathbf{1 4}$ ). The normal fat content of the pancreas is reported to be between 4.6 and $4.9 \%{ }^{52,53}$

\section{T1 Mapping/Relaxometry}

The pancreas has a relatively short T1 relaxation and is hyperintense compared with adjacent soft tissues due to the presence of acinar proteins and rough endoplasmic reticulum. ${ }^{55}$
The $\mathrm{T} 1$ relaxation time of pancreatic tissue increases in diffuse pancreatic pathology such as fibrosis, atrophy, or edema. An increase in $\mathrm{T} 1$ relaxation time decreases the $\mathrm{T} 1$ signal intensity. A subtle decrease in $\mathrm{T} 1$ signal can be an early marker of chronic pancreatitis. ${ }^{56}$ An increase in T1 relaxation time can be semiquantitatively assessed by quantifying the loss of high T1 signal in comparison to control tissue, such as muscle. Quantitative assessment of $\mathrm{T} 1$ relaxation time requires the generation of parametric $\mathrm{T} 1$ maps from which $\mathrm{T} 1$ relaxation time can be assessed by placing an ROI ( - Fig. 15).

\section{T2*/R2* Mapping}

$\mathrm{T} 2 * / \mathrm{R} 2 *$ mapping is widely used in the liver as a measure of parenchymal iron content but large validation studies in the pancreas are lacking. Correlations between logarithmic pancreatic $T 2$ * values and $\beta$-cell function is shown in some studies. ${ }^{57}$ Early research has shown that the pancreatic $R 2^{*}$ values correlate well with liver iron overload and may have potential use as a surrogate marker for hereditary hemochromatosis. ${ }^{58}$

\section{Magnetic Resonance Elastography}

Magnetic resonance elastography (MRE) is "virtual palpation" where the stiffness of tissue is calculated indirectly by calculating the velocity of shear waves propagated through tissue generated by an external source of vibration. It is currently an established technique to measure the stiffness of the liver that acts as an indirect marker for fibrosis. MRE of the pancreas is limited due to the retroperitoneal location of the pancreas and overlying stomach and transverse colon. Chronic pancreatitis and carcinoma pancreas are shown to increase pancreatic stiffness. ${ }^{59}$ Early studies of MRE show
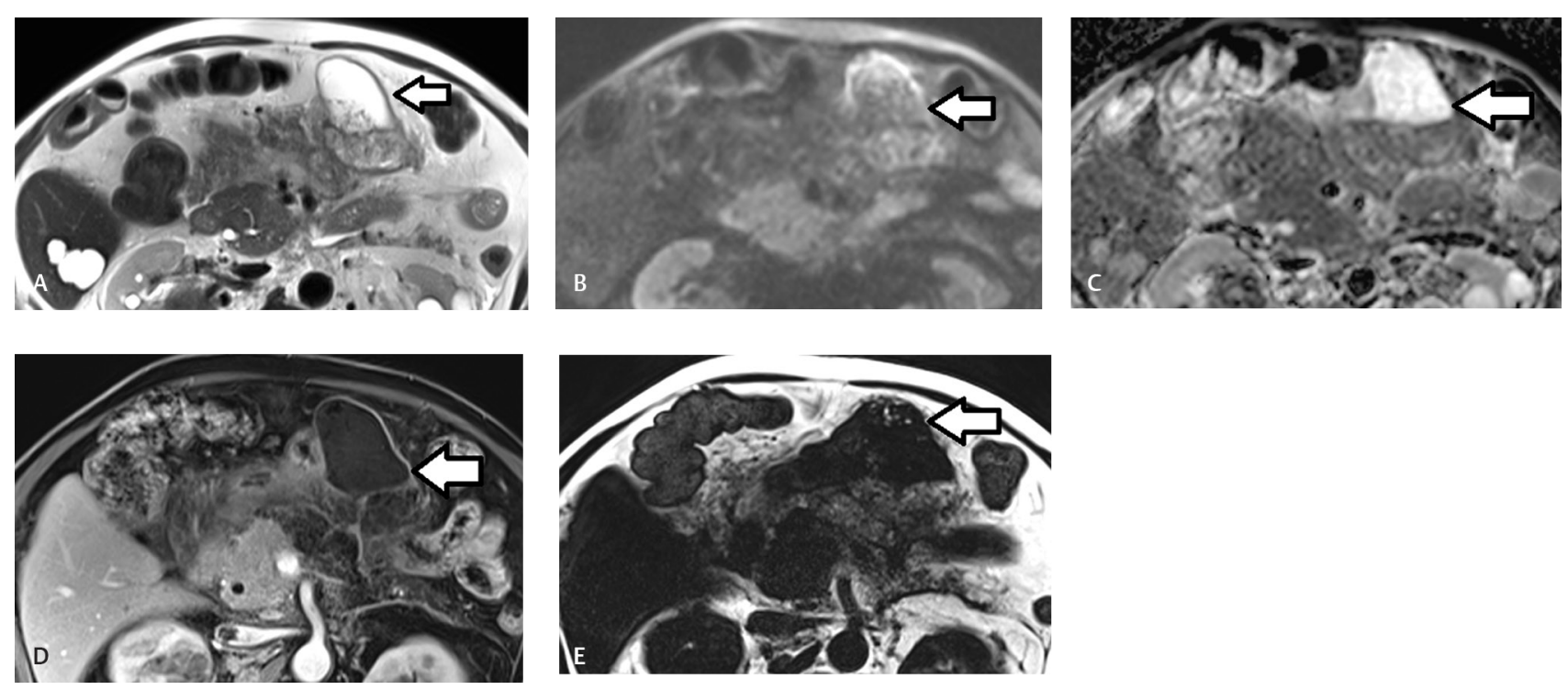

Fig. 12 Demonstration of fat globules within walled off fat necrosis. Axial T2-weighted HASTE image (A) shows a bulky, edematous pancreas with peripancreatic edema. A well-defined cystic intensity lesion with internal debris is noted in transverse mesocolon that shows peripheral rim enhancement on postcontrast T1-weighted image (B) and facilitated diffusion [no hyperintense signal on DWI (C) and high signal on ADC map (D). Dixon fat-only image (E) shows tiny foci of high signal within the lesion suggestive of fat globules (compare with subcutaneous fat). The presence of fat globules differentiated the lesion from pseudocyst and suggested the diagnosis of walled of necrosis. DWI, diffusion-weighted image; HASTE, half Fourier acquisition single-shot turbo spine-echo. 

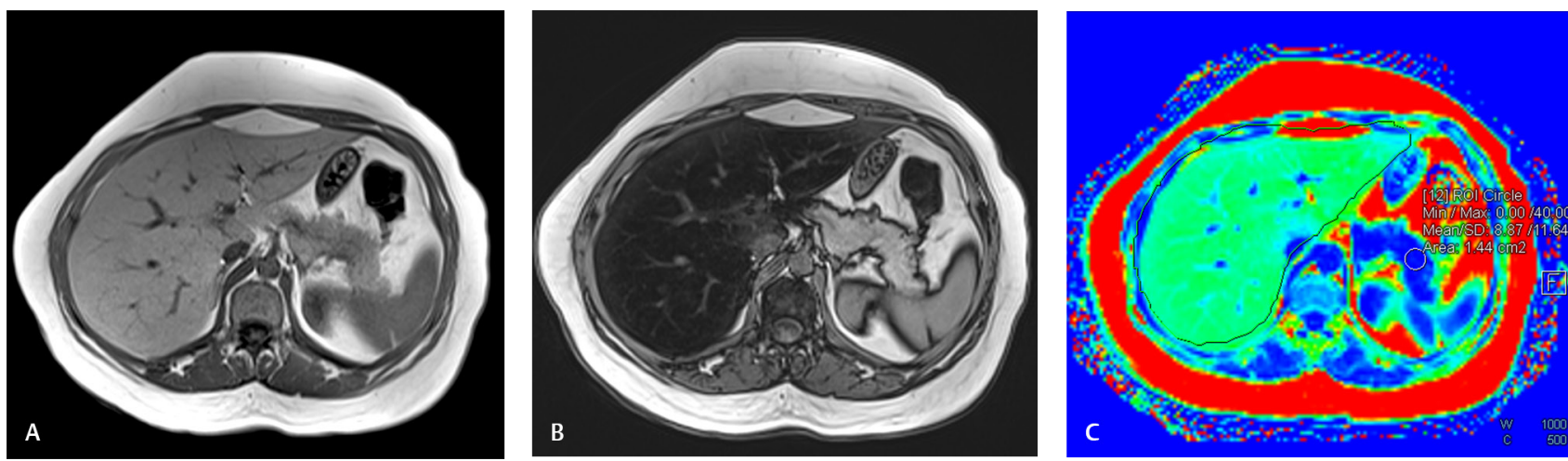

Fig. 13 Normal fat fraction map of the pancreas with fatty liver. In phase (A) and opposed-phase images (B) show diffuse loss of signal in the liver in opposed phase with normal signal in pancreas suggesting fatty deposition of the liver. (C) fat fraction map shows fat deposition in liver (green, compare with visceral fat) with a pancreatic fat fraction of $0.9 \%$, within normal limit.
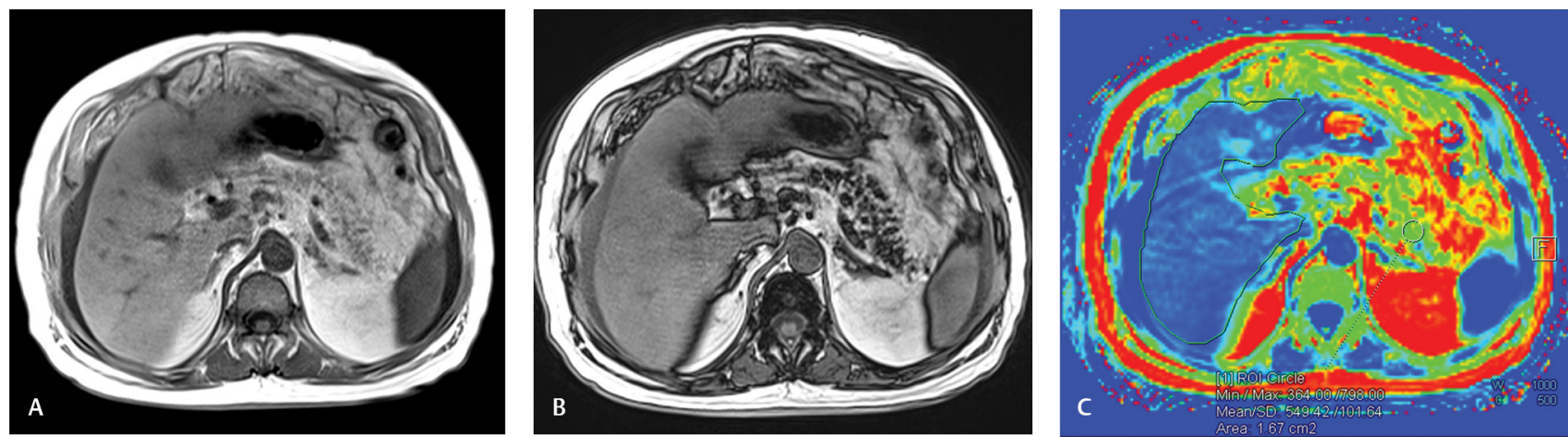

Fig. 14 Steatosis of the pancreas with a normal liver. In phase (A) and opposed-phase images (B) show patchy loss of signal in the pancreas in opposed-phase with a normal signal in liver suggesting pancreatic steatosis. (C) Fat fraction map shows normal liver (blue, compare with image 13) with a pancreatic fat fraction of 5.5\%.
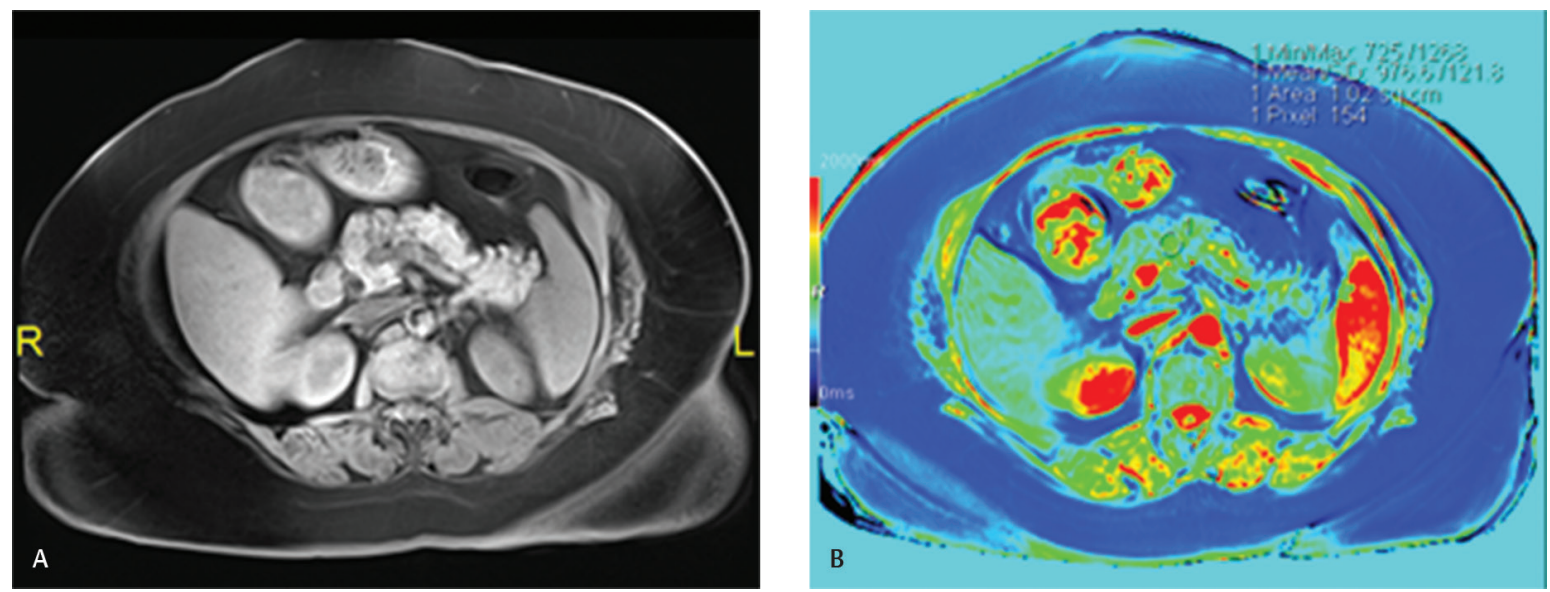

Fig. 15 T1 mapping of normal pancreas. (A) Axial T1-weighted fat-suppressed image shows normal pancreas. (B) ROI placed on the body of the pancreas on T1 map shows T1 relaxation time of 976 milliseconds.

potential in the differentiation between autoimmune pancreatitis and pancreatic adenocarcinoma. ${ }^{60}$

\section{Conclusion}

MRI has a problem-solving role in pancreatic imaging in routine clinical practice. Advanced diffusion techniques can localize and characterize focal and diffuse pathologies serving as a useful adjunct to conventional MRI. Secretin MRCP can improve visualization of ductal anatomy and pathologies and can potentially demonstrate pancreatic leak. Advanced imaging sequences and specialized sequences are useful in the quantitative and semiquantitative assessment of pancreatic fat, iron, fibrosis, and tissue characters that can help in better characterization of diffuse pancreatic diseases in the near future. 


\section{Funding \\ None.}

\section{Conflict of Interest}

None declared.

\section{References}

1 Sandrasegaran K, Lin C, Akisik FM, Tann M. State-of-the-art pancreatic MRI. AJR Am J Roentgenol 2010;195(1):42-53

2 Tscholakoff D, Hricak H, Thoeni R, Winkler ML, Margulis AR. MR imaging in the diagnosis of pancreatic disease. AJR Am J Roentgenol 1987;148(4):703-709

3 Fölsing C, Helmberger T, Sittek H, Reiser M. [Caroli syndrome: diagnostic possibilities of magnetic resonance tomography and MR cholangiopancreaticography] (in German). Rontgenpraxis 1996;49(9):226-228

4 Siddiqui N, Vendrami CL, Chatterjee A, Miller FH, Advanced MR. Advanced MR imaging techniques for pancreas imaging. Magn Reson Imaging Clin N Am 2018;26(3):323-344

5 Tirkes T, Menias CO, Sandrasegaran K. MR imaging techniques for pancreas. Radiol Clin North Am 2012;50(3):379-393

6 Patel BN. Routine MR Imaging for pancreas. Magn Reson Imaging Clin N Am 2018;26(3):315-322

7 Maccioni F, Martinelli M, Al Ansari N, et al. Magnetic resonance cholangiography: past, present and future: a review. Eur Rev Med Pharmacol Sci 2010;14(8):721-725

8 Coppens E, Metens T, Winant C, Matos C. Pineapple juice labeled with gadolinium: a convenient oral contrast for magnetic resonance cholangiopancreatography. Eur Radiol 2005;15(10):2122-2129

9 Papanikolaou N, Karantanas A, Maris T, Gourtsoyiannis N. MR cholangiopancreatography before and after oral blueberry juice administration. J Comput Assist Tomogr 2000;24 (2):229-234

10 Riordan RD, Khonsari M, Jeffries J, Maskell GF, Cook PG. Pineapple juice as a negative oral contrast agent in magnetic resonance cholangiopancreatography: a preliminary evaluation. Br J Radiol 2004;77(924):991-999

11 Pamuklar E Sr, Semelka RC. MR imaging of the pancreas. Magn Reson Imaging Clin N Am 2005;13(2):313-330

12 Winston CB, Mitchell DG, Outwater EK, Ehrlich SM. Pancreatic signal intensity on T1-weighted fat saturation MR images: clinical correlation. J Magn Reson Imaging 1995;5(3):267-271

$13 \mathrm{Kim} \mathrm{BS}$, Kim JH, Choi GM, et al. Comparison of three free-breathing T2-weighted MRI sequences in the evaluation of focal liver lesions. AJR Am J Roentgenol 2008;190(1):W19-W27

14 Bosmans H, Van Hoe L, Gryspeerdt S, et al. Single-shot T2-weighted MR imaging of the upper abdomen: preliminary experience with double-echo HASTE technique. AJR Am J Roentgenol 1997;169(5):1291-1293

15 Semelka RC, Kelekis NL, Thomasson D, Brown MA, Laub GA. HASTE MR imaging: description of technique and preliminary results in the abdomen. J Magn Reson Imaging 1996;6(4):698-699

16 Lee SS, Byun JH, Hong HS, et al. Image quality and focal lesion detection on T2-weighted MR imaging of the liver: comparison of two high-resolution free-breathing imaging techniques with two breath-hold imaging techniques. J Magn Reson Imaging 2007;26(2):323-330

17 Delfaut EM, Beltran J, Johnson G, Rousseau J, Marchandise X, Cotten A. Fat suppression in MR imaging: techniques and pitfalls. Radiographics 1999;19(2):373-382

18 Vitellas KM, Keogan MT, Spritzer CE, Nelson RC. MR cholangiopancreatography of bile and pancreatic duct abnormalities with emphasis on the single-shot fast spin-echo technique. Radiographics 2000;20(4):939-957, quiz 1107-1108, 1112

19 Sodickson A, Mortele KJ, Barish MA, Zou KH, Thibodeau S, Tempany CM. Three-dimensional fast-recovery fast spin-echo MRCP: comparison with two-dimensional single-shot fast spin-echo techniques. Radiology 2006;238(2):549-559

20 Yoon LS, Catalano OA, Fritz S, Ferrone CR, Hahn PF, Sahani DV. Another dimension in magnetic resonance cholangiopancreatography: comparison of 2- and 3-dimensional magnetic resonance cholangiopancreatography for the evaluation of intraductal papillary mucinous neoplasm of the pancreas. J Comput Assist Tomogr 2009;33(3):363-368

21 Soto JA, Barish MA, Yucel EK, Ferrucci JT. MR cholangiopancreatography: findings on 3D fast spin-echo imaging. AJR Am J Roentgenol 1995;165(6):1397-1401

22 Chouhan MD, Firmin L, Read S, Amin Z, Taylor SA. Quantitative pancreatic MRI: a pathology-based review. $\mathrm{Br} J$ Radiol 2019;92(1099):20180941

23 Trout AT, Wallihan DB, Serai S, Abu-El-Haija M. Secretinenhanced magnetic resonance cholangiopancreatography for assessing pancreatic secretory function in children. J Pediatr 2017;188:186-191

24 Tirkes T, Sandrasegaran K, Sanyal R, et al. Secretin-enhanced MR cholangiopancreatography: spectrum of findings. Radiographics 2013;33(7):1889-1906

25 Akisik MF, Sandrasegaran K, Aisen AA, Maglinte DD, Sherman $\mathrm{S}$, Lehman GA. Dynamic secretin-enhanced MR cholangiopancreatography. Radiographics 2006;26(3):665-677

26 Monill J, Pernas J, Clavero J, et al. Pancreatic duct after pancreatoduodenectomy: morphologic and functional evaluation with secretin-stimulated MR pancreatography. AJR Am J Roentgenol 2004;183(5):1267-1274

27 Schraml C, Schwenzer NF, Martirosian P, Claussen CD, Schick F. Perfusion imaging of the pancreas using an arterial spin labeling technique. J Magn Reson Imaging 2008;28(6):1459-1465

28 Kim JH, Lee JM, Park JH, et al. Solid pancreatic lesions: characterization by using timing bolus dynamic contrast-enhanced MR imaging assessment-a preliminary study. Radiology 2013;266(1):185-196

29 Ma W, Li N, Zhao W, et al. Apparent diffusion coefficient and dynamic contrast-enhanced magnetic resonance imaging in pancreatic cancer: characteristics and correlation with histopathologic parameters. J Comput Assist Tomogr 2016;40(5):709-716

30 Barral M, Taouli B, Guiu B, et al. Diffusion-weighted MR imaging of the pancreas: current status and recommendations. Radiology 2015;274(1):45-63

31 Virostko J, Williams J, Hilmes M, et al. Pancreas volume declines during the first year after diagnosis of Type 1 diabetes and exhibits altered diffusion at disease onset. Diabetes Care 2019;42(2):248-257

32 de Freitas Tertulino F, Schraibman V, ArdenghJC, et al. Diffusionweighted magnetic resonance imaging indicates the severity of acute pancreatitis. Abdom Imaging 2015;40(2):265-271

33 Thomas S, Kayhan A, Lakadamyali H, Oto A. Diffusion MRI of acute pancreatitis and comparison with normal individuals using ADC values. Emerg Radiol 2012;19(1):5-9

34 Yencilek E, Telli S, Tekesin K, et al. The efficacy of diffusion weighted Subgroups, imaging for detection of acute pancreatitis and comparison of Gastroenterol, according to Balthazar classification. Turk J Gastroenterol 2014;25(5):553-557

35 Tonolini M, Di Pietro S. Diffusion-weighted MRI: new paradigm for the diagnosis of interstitial oedematous pancreatitis. Gland Surg 2019;8(2):197-206

36 Shinya S, Sasaki T, Nakagawa Y, Guiquing Z, Yamamoto F, Yamashita Y. The efficacy of diffusion-weighted 
imaging for the detection and evaluation of acute pancreatitis. Hepatogastroenterology 2009;56(94-95):1407-1410

37 Borens B, Arvanitakis M, Absil J, et al. Added value of diffusion-weighted magnetic resonance imaging for the detection of pancreatic fluid collection infection. Eur Radiol 2017;27(3):1064-1073

38 Bieliuniene E, Frøkjær JB, Pockevicius A, et al. Magnetic resonance imaging as a valid noninvasive tool for the assessment of pancreatic fibrosis. Pancreas 2019;48(1):85-93

39 Akisik MF, Sandrasegaran K, Jennings SG, et al. Diagnosis of chronic pancreatitis by using apparent diffusion coefficient measurements at 3.0-T MR following secretin stimulation. Radiology 2009;252(2):418-425

40 Muhi A, Ichikawa T, Motosugi U, et al. Mass-forming autoimmune pancreatitis and pancreatic carcinoma: differential diagnosis on the basis of computed tomography and magnetic resonance cholangiopancreatography, and diffusion-weighted imaging findings. J Magn Reson Imaging 2012;35(4):827-836

$41 \mathrm{Oki} \mathrm{H}$, Hayashida Y, Oki H, et al. DWI findings of autoimmune pancreatitis: comparison between symptomatic and asymptomatic patients. J Magn Reson Imaging 2015;41(1):125-131

42 Kartalis N, Lindholm TL, Aspelin P, Permert J, Albiin N. Diffusion-weighted magnetic resonance imaging of pancreas tumours. Eur Radiol 2009;19(8):1981-1990

43 Fukukura Y, Takumi K, Kamimura K, et al. Pancreatic adenocarcinoma: variability of diffusion-weighted MR imaging findings. Radiology 2012;263(3):732-740

44 Wang Y, Miller FH, Chen ZE, et al. Diffusion-weighted MR imaging of solid and cystic lesions of the pancreas. Radiographics 2011;31(3):E47-E64

45 Lemke A, Laun FB, Klauss M, et al. Differentiation of pancreas carcinoma from healthy pancreatic tissue using multiple b-values: comparison of apparent diffusion coefficient and intravoxel incoherent motion derived parameters. Invest Radiol 2009;44(12):769-775

46 Hagmann P, Jonasson L, Maeder P, Thiran JP, Wedeen VJ, Meuli R. Understanding diffusion MR imaging techniques: from scalar diffusion-weighted imaging to diffusion tensor imaging and beyond. Radiographics 2006;26(Suppl 1):S205-S223

47 Nissan N, Golan T, Furman-Haran E, et al. Diffusion tensor magnetic resonance imaging of the pancreas. PLoS One 2014;9(12):e115783

48 Li X, Zhuang L, Zhang X, et al. Preliminary study of MR diffusion tensor imaging of pancreas for the diagnosis of acute pancreatitis. PLoS One 2016;11(9):e0160115
49 Kartalis N, Manikis GC, Loizou L, et al. Diffusion-weighted MR imaging of pancreatic cancer: A comparison of monoexponential, bi-exponential and non-Gaussian kurtosis models. Eur J Radiol Open 2016;3:79-85

50 Noda Y, Kanematsu M, Goshima S, et al. Diffusion kurtosis imaging of the pancreas for the assessment of HbA1c levels. J Magn Reson Imaging 2016;43(1):159-165

51 Riffel P, Michaely HJ, Morelli JN, et al. Zoomed EPI-DWI of the pancreas using two-dimensional spatially-selective radiofrequency excitation pulses. PLoS One 2014;9(3):e89468

52 Kühn JP, Berthold F, Mayerle J, et al. Pancreatic steatosis demonstrated at MR imaging in the general population: clinical relevance. Radiology 2015;276(1):129-136

53 Heber SD, Hetterich H, Lorbeer R, et al. Pancreatic fat content by magnetic resonance imaging in subjects with prediabetes, diabetes, and controls from a general population without cardiovascular disease. PLoS One 2017;12(5):e0177154

54 Nadarajah C, Fananapazir G, Cui E, et al. Association of pancreatic fat content with type II diabetes mellitus. Clin Radiol 2020;75(1):51-56

55 Watanabe H, Kanematsu M, Tanaka K, et al. Fibrosis and postoperative fistula of the pancreas: correlation with MR imaging findings-preliminary results. Radiology 2014;270(3):791-799

56 Tirkes T, Lin C, Fogel EL, Sherman SS, Wang Q, Sandrasegaran K. T1 mapping for diagnosis of mild chronic pancreatitis. J Magn Reson Imaging 2017;45(4):1171-1176

57 Au WY, Lam WW, Chu W, et al. A T2* magnetic resonance imaging study of pancreatic iron overload in thalassemia major. Haematologica 2008;93(1):116-119

58 Henninger B, Rauch S, Zoller H, Plaikner M, Jaschke W, Kremser C. $R 2^{*}$-relaxometry of the pancreas in patients with human hemochromatosis protein associated hereditary hemochromatosis. Eur J Radiol 2017;89:149-155

59 An H, Shi Y, Guo Q, Liu Y. Test-retest reliability of 3D EPI MR elastography of the pancreas. Clin Radiol 2016;71(10):1068. e7-1068.e12

60 Shi Y, Cang L, Zhang X, et al. The use of magnetic resonance elastography in differentiating autoimmune pancreatitis from pancreatic ductal adenocarcinoma: A preliminary study. Eur J Radiol 2018;108:13-20 